\title{
Spread Mind and Causal Theories of Content
}

\author{
Krystyna Bielecka \\ Institute of Philosophy, University of Warsaw \\ kikab[]gazeta.pl \\ Received December 2013; accepted September 2014; published Autumn 2014.
}

\begin{abstract}
In this paper, I analyze a type of externalist enactivism defended by Riccardo Manzotti. Such radical versions of enactivism are gaining more attention, especially in cognitive science and cognitive robotics. They are radical in that their notion of representation is purely referential, and content is conflated with reference. Manzotti follows in the footsteps of early causal theories of reference that had long been shown to be inadequate. It is commonly known that radical versions of externalism may lead to difficulties with the notion of representation, especially if they cannot help themselves with the notion of syntax. I argue that a type of externalism present in Manzotti's enactivism may well lead to anti-representationalism.
\end{abstract}

Keywords: anti-representationalism; enactivism; causal spread; content; presentation.

In this paper, I analyze a kind of externalist enactivism defended, for example, by Riccardo Manzotti. Such radical versions of enactivism are gaining more attention, especially in cognitive science. However, it is not always appreciated that they involve radically externalist approaches to meaning. They are radical in that their notion of representation is purely referential, and content is conflated with reference. It is commonly known that radical versions of externalism may lead to difficulties with the notion of representation, especially if they cannot help themselves with the notion of syntax (or syntactic form, as in (Fodor 2008)). Without such notion, however, the enactivist view may be hardly tenable. 
I argue that a type of externalism present in Manzotti's enactivism may well lead to anti-representationalism. Admittedly, he does not use the term "representation" and argues that the notion of "presentation" should replace it (Manzotti 2006). However, his "presentation" seems to play the role traditionally assigned to representation. Whether we call it "presentation" or "representation", the deeper problem is that it does not seem to answer the basic question of what its specific job would be, as opposed to any other factor that mediates perception and action. For this reason, his "presentational" view may collapse to anti-representationalism, especially in light of his arguments for mind's causal spread.

The aim of this paper is, first, to show some undesired consequences that such a kind externalism has for mental representation. Second, I want to show that even presentational or anti-representational views are in trouble when they help themselves with the notion of causation to define representation or presentation (or its anti-representational substitute). What is interesting, externalists such as Manzotti follow in the footsteps of early causal theories of reference that have long been shown to be inadequate. To justify this claim, I will show some similarities between radically externalist enactivism and early causal theories of Dretske (Dretske 1982) and Stampe (Stampe 1977). I will conclude by pointing out that some externalist theories, such as Manzotti's, are not acceptable because the problems they create are simply unsolvable.

\section{Meaning and content}

In this paper, I will appeal to two notions: meaning and content. Some initial explication is in order. These notions will be characterized as follows:

By "content" I will understand a non-formal property of a sign that allows us to distinguish two different expressions, even if they have the same reference. As a result, two expressions (e.g. "George Bush" and "ex-president") cannot be substituted in referentially opaque contexts, i.e.:

George Bush voted for Barack Obama during the last election in the USA.

The US ex-president voted for Barack Obama during the last election in the USA.

By meaning, I understand - just like Frege - reference (so a meaning of a "cat" is every instance of a cat, either black, white, brown, and so forth).

A theory of representation that does not include meaning or content as aspects of representation usually leads to inexorable difficulties. This is the reason why radical internalism (by eliminating meaning from the purview of the theory of mental representation) still remains so controversial. Today, the 
proponents of radical internalism have to offer additional reasons to justify their view against common objections (Segal 2000; Kriegel 2008) (I do not want to claim that it's impossible to defend radical internalism; all I imply is that this view simply requires further justification). Others either opt for twofactor theories (Block 1987; Block 1981) and juxtapose narrow content with a theory of reference or reject internalism altogether, as in the long-arm, or externalist, theory of representation (Greenberg and Harman 2006). While the latter tries to extend the notion of content so as to include the roles traditionally played by the notion of reference, the former tries to establish an appropriate relationship between the meaning and content of representations (which is not to say that this approach is entirely successful in this regard, see (Fodor and Lepore 1992)).

\section{Manzotti's rejection of content}

Before I proceed to present Manzotti's views on mental representation, some elucidation is in order. Riccardo Manzotti is mainly known for his work on consciousness, and he defends the view that phenomenal consciousness is also extended in space. In that, he goes further than (Clark and Chalmers 1998), who believe that only the cognitive mind is extended, not phenomenal consciousness. Yet Manzotti's view is systematic enough to imply a fairly clear account of representation (or "presentation" as he calls it). Also, his account of enactivism and externalism seems to be gaining popularity among roboticists and cognitive scientists (Manzotti's being roboticist himself). For this reason, it may be instructive to analyze the conceptual framework implied by a growing body of cognitive research. Here, I will focus only on his views on "presentation”, putting aside his ontological or metaphysical position, as it is quite complex. I do not think that anything really important hinges on the fact that I do not analyze his process metaphysics at any length here. By avoiding it, I will simply deal with methodological assumptions that he shares with other enactivists, who consider the world to be its best representation (Brooks 2003). It will be instructive to see what the cash value of this claim is, regardless of metaphysical views of its proponents.

As a radical externalist, Manzotti rejects content in his account of representation. In this sense, his view is similarly extreme as radical internalism, which rejects meaning but not content. Manzotti's view is, in other words, purely referential. There are other proponents of purely referential accounts of representation, one of the most prominent being (Fodor 2008). The most important difference is that in contrast to Fodor, Manzotti does not seem to find any use for the notion of the syntactic form to explicate the why "George W. Bush" and "The US ex-president", even if co-referential, are not substitutable in referentially opaque contexts, whereas Fodor does. Also, Fodor has long 
rejected the simplistic version of the causal theory of content that Manzotti seems to presuppose.

Most naturalistic theories of representation find themselves in trouble when they try to reduce representational relations to relationships of similarity or covariance (Fodor 1984). Manzotti supports the covariance theory in its causal version even if he rejects the Cartesian gulf between the subject and the object. He argues that on the latter view, the emergence of representation seems to be a miracle:

Up to now, the nature of the [representational - K.B.] relation is a tantalizing mystery. Different solutions have been proposed: correlation, causation, lawlike causation, emergence, identity, supervenience. None has proved to be completely satisfactory. (Manzotti 2006: 47)

Manzotti insists that instead of "representation" we should say "presentation". He claims that representation

(...) is used as an explanatory notion with a meaning of its own - a representation is something that presents (or re-presents) something else. (Manzotti 2003: 289)

He understands mind as spread physically and spatiotemporally beyond the skin. He illustrates this claim by using the metaphor of a rainbow:

As a unity, although constituted by a series of physical drops of water in space reflecting the light in a certain way, cannot be defined without knowing where and how it will be seen. (Manzotti 2006: 50)

For this reason:

(...) drops of water reflect the sunlight in the same manner, yet only those which have a particular geometrical relation to the observer, due to his/her position and to the direction of the sun rays, are seen as part of the rainbow (...) A given rainbow exists only when the observer is in a given position with respect to the external stimulus. (Manzotti 2006: 50)

In his view, there is no separation between mind and the world because what a particular mind perceives is in the continuous process common for particular minds and the world. What is more (and more worrying!), everything that an individual mind can perceive is veridical. He believes that everything we have in memory comes from the world:

According to the process view presented here, memory and mental imagery have a phenomenal aspect because they are "perception delayed in time". Whenever we remember something, an uninterrupted causal chain originated in an object/event/state of affairs reaches its end in the brain. (Manzotti 2006: 65) 
There are researchers who also think that memory does not require representation, so he is not alone here; however, they do not seem to claim that memory should be identified with perception (see (Freeman 1991) on the olfactory memory of rabbits).

However, Manzotti needs to say what illusion is (or at least seems to be if all perception is veridical indeed):

I propose to see illusions as instances of infrequent correlations among physical events. Slightly more formally, I propose to see illusions as situations where an event $\mathrm{C}$ - normally perceived in conjunction with some other event A - is exceptionally perceived in conjunction with some other event B. (Manzotti 2006: 68)

And then he concludes:

It is supposed that A is perceived instead of B. However what is perceived is, as in normal situations, $C$. The hypothesis of illusions is unnecessary and the continuity with the external physical world is maintained. (Manzotti 2006: 68)

But the claim that one can explain away misrepresentation in such terms is deeply problematic. Explaining illusions, or any malfunction, in terms of frequency is controversial. Take a simple biological example: sperm. Very few sperm actually serve their purpose (Millikan 1984: 29). Similarly, beavers may splash their tails much more frequently than there is real danger, but it is adaptive to splash your tail if you are a beaver. Infrequency cannot define what illusion is; to see that it is enough to realize that what people perceive as movies, are actually still images displayed quickly one. If Manzotti was right about illusions, then the illusion of movement that we experience when watching a movie would go after a sufficiently long exposure to it. However, movie lovers do not seem to experience disillusionment that there is no movement even if they spend whole days in the theater.

Even if we were to accept the view that illusions are just special cases of veridical perception caused by infrequent correlations, how could we check which cases are more correct and why? Imagine an almost blind person. His or her visual perception functions incorrectly almost all the time, so his or her perception is almost never correlated with the world events. But how does his or her case differ from the case of people with normal vision that see a stick in the water as bent? Classifying both cases as illusions would be a mistake. We would rather say that the second case is a common perceptual illusion while the first is a physiological inability to perceive objects. And how does it differ from cases when I mistake a roe deer in a forest to be a running horse? Memory illusions, in which a person reports of a past event that seriously deviates from the event's actual occurrence, seem to be problematic in this view as well (Roediger 1996). They may be as frequent as one wishes. 
Are non-perceptual mistakes possible in Manzotti's view? It is hard to see how any non-perceptual mistakes could exist according to his view if all representation (or rather presentation) is based on perception. Manzotti is in pains to stress that there is continuity between mental presentation and perception. But some of our presentations do not seem to veridical, even if perception is not affected. Take the Capgras delusion (Hirstein and Ramachandran 1997). The Capgras delusion appears when a person consciously recognizes faces (this presentation is veridical) but because of the malfunction of the limbic system, there is a lack of an appropriate emotional response. As a result, a person looking at a face of her or his family member thinks she or he is looking at a doppelganger. Now, perceptual processes are fine, but we have a complex process that causes people to deny that they recognize their family members as family members. They recognize them only as doppelgangers of family members. Frequency has nothing to do with it.

As a consequence, the view that presentation is continuous with perception allows for no simple falsity in presentations. Even having empty concepts, such as Pegasus, seems to be an inexplicable anomaly for this theory. Just like Dretske had to say that there is no such thing as false information (Dretske 1982), Manzotti is pressed to deny false presentations. But then what is the cash value of such a notion of presentation? While Dretske appreciates the fact that agents do misrepresent (Dretske 1986) and claims that this representation is not reducible to semantic information (or natural meaning), Manzotti simply bites the bullet and says that there is no such thing as misrepresentation. But what explanatory use could his notion of presentation have? Definitely not the one that is traditionally associated with the notion of mental representation.

Manzotti defines the relationship between the mind and the world in terms of a causal network; but causal factors seem to be apprehended in a holistic fashion:

If causal properties are not located on objects but depend on the causal network as a whole, then they cannot be located on a particular object. In a similar way, instead of being atomistically separate and autonomous, causes and effects become different ways of looking at processes. (Manzotti 2006: 54)

On Manzotti's view, there is no possibility to distinguish some causes as the causes of this particular presentation. This is so because of two reasons. First, it is difficult to determine the meaning of presentation in a continuous, neverending process; second, everything is always relative to the particular mind. I will show the detrimental consequences for understanding presentation in these terms in detail below. 


\section{The disjunction problem}

Imagine a person who calls water "vodka" by mistake. What is an extension of his or her term "water”? A priori, we have three possibilities:

a) "Water" denotes water

b) "Water" denotes water or vodka (water v vodka)

c) "Water" denotes vodka

Intuitively, only the answer (a) is correct. But a causal theory of reference does not give us any criteria necessary to fix the denotation in this standard manner. It cannot answer our question of what still does belong to the extension of the term $\mathrm{T}$ and what a new thing that does not belong to the extension of $\mathrm{T}$ is. This is where the so-called disjunction problem appears. There is no possibility to distinguish expanding the extension of the term from a mistake in using it. Actually, the causal theories, if they rely on the covariation of the use of the term $\mathrm{T}$ and the occurrence of referents (the simplified version of which is Manzotti's frequency view), have to embrace the answer (b). The extension always grows, and it's impossible to shrink it again. As the set of referents grows, our description of reference needs to include more and more disjunctions. Thus, the disjunction problem is an essential problem for causal theories as well as any theories that explicate representation in purely causal terms (Fodor 1984).

The informational semantics defended by Dretske (Dretske 1982) and Stampe (Stampe 1977) assumed that representation is reducible to information and that there is no such thing as false information. But, it means that there is no misrepresentation, and this is hardly credible. For this reason, informational semantics has been criticized as deeply flawed (Godfrey-Smith 1989). Manzotti's claim that presentation is basically reducible to veridical perception leads to exactly the same problem. Dretske later even admitted that mere causal relations are not enough to explicate the notion of representation that are applicable to misrepresentation (Dretske 1986). Manzotti, however, cannot escape the problem at all. All he can do is deny that there is misrepresentation.

\section{Anti-representationalism and misrepresentation}

It is notable that the same arguments to effect that the mind is a spread entity are also used by anti-representationalists in order to justify their view (e.g., Paco Calvo, who even uses the same term "causal spread" that was introduced earlier by Andy Clark and Mike Wheeler (Garzon 2008; Clark and Wheeler 1998)). It does not take much to see that Manzotti's theory of "presen- 
tation" is rather anti-representational or at least too weak to defend a concept of representation.

Anti-representationalists such as Calvo stress the continuity between the world and the mind; according to them, there is no difference between on-line and off-line representations. On-line representations appear only in the immediate presence of an object perceived, while off-line ones are present when the object is absent. The latter are taken to be paradigmatic cases of representations. By taking continuity seriously, we can easily show that there is always some link between the representational state and the previous state. The causal chain is actually never broken. Then, however, it's hard to distinguish the off-line representations from the on-line ones. It appears as if the presence of representations is always immediate. As the same kind of continuity is presupposed by Manzotti, it is not so hard to see that his notion of "presentation" has to be quite weak. It is exactly the same kind of entity as Clark's "on-line representation.” But, as Calvo argues, one can explain phenomena with online representations by recourse to real-time dynamics, and in his view, this kind of theoretical entity seems to play no specific job assigned for representation at all. Let me elaborate on this.

In his recent book, Ramsey argued that tracking theories of representation (that take indicators to be paradigmatic cases of it) have difficulties with specifying what is specifically representational about them (Ramsey 2007). The idea that they influence behavior seems clear, but gravity does as well. The danger is that such theories may be too thin, having no role for content at all (note that I do not embrace Ramsey's argument that Dretske's or Millikan's teleosemantics is trivialized for this reason, as there is a role for content in their theories; but this is a topic for another discussion). All in all, dispensing with content and playing with continuity may be detrimental.

Interestingly, Fodor has recently also denounced any role for content, taking a purely referential view (Fodor 2008). However, there is a substitute for content in his theory. The form of the representation seems to differentiate "the US ex-president" and "George W. Bush" quite clearly. Just because Fodor can explain referential opacity by appeal to the form, his view does not suffer from the same objections that are detrimental to other referential views on representation. However, note that it is not possible for Manzotti to endorse such a view at all. He sees no role for vehicles of presentation (Manzotti 2006: 60 ) and tries to make them as dynamic as possible. It seems that the form of presentation would also be quite spread in time and space. Manzotti, for this reason, appears to think that the notion of vehicle and its form is dispensable (note that this is not in general accepted by all proponents of the dynamical view on cognition; see e.g. (Rączaszek-Leonardi 2009; Deacon 2011)). But then, referential opacity remains an inexplicable mystery for his theory. 
Moreover, what lacks in Manzotti's theory is a satisfactory concept of misrepresentation. Even if we agreed that misrepresentation is an on-line representation located in a continuous process, his account of misrepresentation in terms of frequency would be totally unsatisfactory. Illusions, delusions, hallucinations, or simple fallacies in reasoning can appear very often and some of them seem to be innate (e.g. gambler's fallacy).

It's worth noticing that anti-representationalism also cannot avoid describing these phenomena and their description in terms of a continuous causal chain or process is not informative. Understanding representation in terms of spatiotemporally spread chain seems to be drastically incomplete. Representational theories do not state that representation is just veridical perception and it is as if anti-representationalists try to avoid explaining what else should be added but that perception will help describe fallacies or delusions.

Without a satisfactory notion of misrepresentation, no account of representation is acceptable (Dretske 1986). But this is also true of accounts of cognition, anti-representational included. A representational theory that denies the very possibility of there being any misrepresentation is a theory that deflates the concept of representation and trivializes it completely. Such representations may be indeed epiphenomenal. If you want to explain my behavior only by recourse to true beliefs, then I wish you good luck, especially because some of these beliefs are not mine at all.

\section{Conclusion}

In this paper, I argued that some radical externalist theories, such as Manzotti's theory of "presentations", are equally misconceived as early causal theories of reference defended by Dretske or Stampe. I want to draw two general conclusions from this fact. These conclusions are pertinent to radical externalist theories such as Manzotti's as well as to theories of representation in general, enactivist or not.

First, my criticism of Manzotti's theory may apply to any radical enactivist theories that are anti-representational or as weakly representational as Manzotti's. The similarity between Manzotti's enactivism and the early causal theories of reference shows that they both deflate representation. The ability to tackle misrepresentation is what should be required from any theory of representation that is psychologically plausible.

Second, it is remarkable that theories of representation that reject either content or meaning have difficulties with explaining what job the representation has qua representation in the cognitive system. To reject meaning (as radical internalists do) is to make it difficult to understand the relationship of representations and the world in which the cognitive system finds itself in. The 
theories of this kind are therefore solipsistic. But to reject content (as radical externalists do) is to make misrepresentations and false representations impossible, although the problem with relation to the world does not arise.

Note that Manzotti's troubles with misrepresentation and content are not at all implied simply by his enactivism. They arise because of a grossly simplified view on "presentation" that seems to take the claim that the world is its best presentation seriously. If this is so, then presentation cannot be wrong. However, this also means that there cannot be learning, as learning implies the ability to correct previous mistakes and recognize them as such. If enactive approach is the one that recognizes the crucial inter-dependency between the autonomous agent and the world it finds itself in, then many theories of representation seem to be compatible with it (and some of them deal explicitly with the disjunction problem or misrepresentation; see (Bickhard 2008; Bickhard 1993; Anderson and Rosenberg 2008)). The trouble is that it is all too easy to radically deny the need for representation. I dare say that this means denying the need for cognition and learning as well, but that is a matter for further discussion.

\section{References}

Anderson, M.L., and Gregg Rosenberg. 2008. Content and Action: The Guidance Theory of Representation. Journal of Mind and Behavior 29 (1-2): 55-86.

Bickhard, M.H. 1993. Representational Content in Humans and Machines. Journal of Experimental \& Theoretical Artificial Intelligence, 5 (4) (October 1): 285-333. doi:10.1080/09528139308953775.

Bickhard, M.H. 2008. The Interactivist Model. Synthese, 166 (3): 547-591. doi:10.1007/s11229-008-9375-x.

Block, N. 1981. Psychologism and Behaviorism. The Philosophical Review, 90 (1) (January 1): 5-43.

Block, N. 1987. Advertisement for a Semantics for Psychology. Midwest Studies in Philosophy, 10 (1) (September): 615-678. doi:10.1111/j.1475-4975.1987.tb00558.x.

Brooks, R. A. 2003. Intelligence with Representation. Philosophical Transactions. Series A, Mathematical, Physical, and Engineering Sciences, 361 (1811) (October): 238195. doi:10.1098/rsta.2003.1257.

Clark, A., and D. J. Chalmers. 1998. The Extended Mind. Analysis, 58 (1): 7-19.

Clark, Andy, and Michael Wheeler. 1998. Bringing Representation back to Life. From Animals to Animats 5-Proceedings of the Fifth International Conference on Simulation of Adaptive Behavior. R. Pfeifer, B. Blumberg, J.-A. Meyer, and S. W. Wilson, eds. 3-12. Cambridge, Mass.: MIT Press.

Deacon, T.W. 2011. The Symbol Concept. Oxford Handbook of Language Evolution, edited by M. Tallerman and K. Gibson. Oxford.

Dretske, F. I. 1982. Knowledge and the Flow of Information. 2nd ed. Cambridge, Mass.: MIT Press.

Dretske, F. I. 1986. Misrepresentation. Belief: Form, Content, and Function. R. Bogdan, ed. 17-37. Oxford: Clarendon Press. 
Fodor, J. A. 1984. Semantics, Wisconsin Style. Synthese 59 (3) (June): 231-250. doi:10.1007/BF00869335.

Fodor, J. A. 2008. LOT 2: The Language of Thought Revisited. New York: Oxford University Press.

Fodor, J. A., and E. Lepore. 1992. Why Meaning (Probably) Isn’t Conceptual Role. Mind \& Language, 6 (4): 328-343.

Freeman, W. J. 1991. The Physiology of Perception. Scientific American, 264 (2): 78-85.

Garzon, F. C. 2008. Towards a General Theory of Antirepresentationalism. The British Journal for the Philosophy of Science, 59 (3) (September 1): 259-292. doi:10.1093/bjps/axl007.

Godfrey-Smith, Peter. 1989. Misinformation. Canadian Journal of Philosophy, 19 (4): 533-550.

Greenberg, M., and G. H. Harman. 2006. Conceptual Role Semantics. The Oxford Handbook of Philosophy of Language. E. Lepore and B. Smith, eds. 295-322. Oxford: Oxford University Press.

Hirstein, W., and V. S. Ramachandran. 1997. Capgras Syndrome: A Novel Probe for Understanding the Neural Representation of the Identity and Familiarity of Persons. Proceedings: Biological Sciences, 264 (1380) (March 22): 437-444. doi: $10.2307 / 50434$.

Kriegel, U. 2008. Real Narrow Content. Mind \& Language, 23 (3) (June): 304-328. doi:10.1111/j.1468-0017.2008.00345.x.

Manzotti, R. 2003. A Process-Based Architecture for an Artificial Conscious Being. Process Theories: Crossdisciplinary Studies in Dynamic Categories. Johanna Seibt, ed. 285-312. Dordrecht: Kluwer Academic Publishers.

Manzotti, R. 2006. An Alternative View of Conscious Perception. Journal of Consciousness Studies, 13 (6): 45-79.

Millikan, R.G. 1984. Language, Thought, and Other Biological Categories: New Foundations for Realism. Cambridge, Mass.: The MIT Press.

Ramsey, W.M. 2007. Representation Reconsidered. Cambridge: Cambridge University Press. doi:10.1017/CBO9780511597954.

Rączaszek-Leonardi, J. 2009. Symbols as Constraints: The Structuring Role of Dynamics and Self-Organization in Natural Language. Pragmatics \& Cognition, 17 (3): 653676. doi:10.1075/p\&c.17.3.09ras.

Roediger, H.L. 1996. Memory Illusions, 100 (35): 76-100.

Segal, G. 2000. A Slim Book about Narrow Content. Cambridge Mass.: MIT Press.

Stampe, D.W. 1977. Toward a Causal Theory of Representation. Midwest Studies in Philosophy, 2 (1) (September): 42-63. doi:10.1111/j.1475-4975.1977.tb00027.x. 